\title{
Propuesta metodológica para el examen, registro y representación gráfica de los brocados aplicados
}

\author{
Ana Carrassón López de Letona, Maite Barrio, Ion Berasain, Kyra Borst, Laura Ceballos, Mercedes \\ Cortázar, Isabel Cubillas, Ingrid Geelen, Teresa Gómez, María José González, Ana Laborde, \\ Agnès Le Gac, Camino Roberto, Emilio Ruiz de Arcaute, Ma Dolores Sanz, Erica Sartori, Delphine \\ Steyaert
}

Resumen: La falta de una fórmula común entre los profesionales y estudiosos que trabajan con los brocados aplicados ha llevado al grupo de trabajo europeo de especialistas en escultura policromada a definir un procedimiento para el examen, registro y representación gráfica que permita profundizar en el estudio de esta delicada y frágil técnica a través de una información normalizada. Este trabajo recoge los aspectos del brocado aplicado que han de ser examinados; cómo éstos pueden ser recogidos y registrados atendiendo a las condiciones y estrategias más inocuas para la obra y propone, por último, un procedimiento para su representación gráfica.

Palabras clave: brocado aplicado, metodología de estudio, registro, representación gráfica, conservación-restauración, policromía

\section{Methodological proposal for the examination, registration and graphic representation of the applied brocades}

Abstract: The lack of a common formula among professionals and scholars for the study of applied brocades has led the European working group of specialists in polychrome sculpture to define a standardized procedure for examination, registration and graphic representation that allows a deeper understanding of this delicate and fragile technique. This work gathers the aspects of the applied brocade that have to be examined; how these can be collected and registered according to the most harmless conditions and strategies and proposes a procedure for their graphic representation.

Keyword: applied brocade, methodology, registration, graphic representation, conservation-restoration, polychromy

\section{Proposta metodológica para exame, registo e representação gráfica dos brocados aplicados}

Resumo: A falta de uma fórmula comum entre os profissionais e estudiosos que trabalham com brocados aplicados levou o grupo de trabalho europeu de especialistas em escultura policromada a definir um procedimento de exame, registo e representação gráfica que permita aprofundar o estudo desta delicada e frágil técnica através de uma informação normalizada. Este trabalho reúne os aspetos do brocado aplicado que devem ser examinados; como estes podem ser recolhidos e registados de acordo com as condições e estratégias mais inócuas para a obra e propõe, por fim, um procedimento para a sua representação gráfica.

Palavras-chave: brocado aplicado, metodologia de estudo, registo, representação gráfica, conservação-restauro, policromia 


\section{Introducción}

Este artículo es fruto y resultado del interés y de los debates mantenidos por los miembros del Grupo Europeo de Policromía en Relieve (GEPR) durante las dos jornadas celebradas en 2018 y 2019. La mayoría de sus miembros han formado parte de anteriores encuentros de profesionales interesados en el estudio, la conservación y la restauración de la escultura policromada. Provienen de distintas instituciones públicas, universidades, empresas, centros de formación y de conservación y restauración de Europa. Han formado parte del Grupo latino de escultura policromada y participado en numerosas iniciativas de ámbito europeo como el proyecto "RAPHAEL", en torno a la policromía barroca ${ }^{[1]}$, o el Seminario Internacional sobre Retablos organizado por el Getty Conservation Institute y el Instituto Andaluz del Patrimonio Histórico en $2002{ }^{[2]}$. Sus miembros tienen una larga trayectoria de participación en foros profesionales promovidos por el International Institute for Conservation of Historic and Artistic Works y en grupos de trabajo del Committee for Conservation (ICOMCC), así como en numerosas publicaciones especializadas sobre policromía ${ }^{[3]}$.

El brocado aplicado es una técnica que, aunque se elabora de manera independiente como otras aplicaciones, forma parte del proceso polícromo de una obra. Su presencia está documentada especialmente en la escultura de madera y de piedra y en los retablos, sin embargo se encuentran también en menor medida en pintura sobre tabla, muro y mobiliario. Atendiendo a los últimos estudios apuntamos brevemente que, aunque se conocen ejemplos anteriores (Nadolny 2003: 188 n. 93; Geelen \& Steyaert 2011:25-29), el uso generalizado del brocado aplicado se da en un periodo histórico de cronología muy concreta, desde finales del siglo XIV hasta alcanzar su etapa de mayor desarrollo entre mediados del siglo XV y el primer tercio del siglo XVl, coincidiendo con el gótico final y el protorrenacimiento; después de estas fechas, salvo algunas excepciones tardías, desaparece esta técnica polícroma definitivamente (González-López 2000: 68; Gómez 2001: 576). En cuanto a su origen geográfico se considera que se creó en Centroeuropa (Gómez y Gómez 2005: 271-272); desde los talleres nórdicos de Flandes se expandió rápidamente a otros países, con especial presencia en la Península Ibérica, donde se localizan en la antigua Corona de Aragón los ejemplos documentados más tardíos (1597) (Roberto 2014: 125, 131).

El término compuesto "brocado aplicado" define una técnica polícroma en relieve que imita los tejidos lujosos de moda entre las clases altas. El brocado se efectúa a través de moldes y posteriormente se aplica en la obra durante el proceso polícromo. Se realiza a partir de una matriz de madera, metal o piedra, donde se graba el motivo y sobre la que se dispone una lámina de estaño que por presión o por percusión toma su forma. Después se aplica en el reverso un relleno compuesto con distintos productos o mezclas, blandos y traslúcidos, como cera de abejas, cera y resina o bien mezclas duras y opacas de yeso y pigmentos aglutinados con aceite o cola animal (Frinta 1963: 136-149; González-López 2000: 73; Rodríguez 2009: 207-209; Steyaert, Sanyova, Saverwyns, Geelen y Glaude 2011: 152-159; Roberto 2014: 81-271). Una vez extraído el brocado de la matriz, la cara visible se dora o platea al mordiente, a veces el estaño puede llevar solo color o un barniz (Barrio y Berasain 2006: 40); frecuentemente se acaban con veladuras o colores opacos sobre el oro para resaltar el diseño ${ }^{[4]}$. Los brocados se disponen sobre las obras yuxtapuestos o bien aislados, presentando estos últimos diversidad de formas ${ }^{[5]}$.

Su estudio está condicionado por varios factores, tales como la adaptación de los brocados a los volúmenes de las obras, su frecuente estado de deterioro y la presencia de repintes, barnices y acumulaciones de suciedad. Las dificultades de accesibilidad a las obras y una insuficiente o nula iluminación para poder observarlos, son situaciones asociadas comúnmente a esta técnica y cuya interrelación dificulta sobremanera su examen.

Cabe sumar a estas dificultades la inexistencia de unas referencias gráficas normalizadas de representación del brocado aplicado, tanto de sus características técnicas como del diseño de prototipos, que permita al colectivo de profesionales e investigadores interesados en su conocimiento disponer de suficientes datos de referencia, fiables y medibles, que posibiliten cotejarlos y ayuden a avanzar en sus conclusiones.

La comparación entre modelos es una fuente inestimable de información, ya que nos puede permitir seguir el rastro de un mismo motivo a lo largo de un periodo cronológico amplio (Geelen \& Steyaert 2011: 85-103; Barrio y Berasain 2018: 3436) o de una zona geográfica concreta, agrupar obras por la utilización de los mismos patrones o incluso establecer autorías en torno a un mismo taller o policromador en el caso del uso de la misma matriz (Geelen \& Steyaert 2011: 105-117; Roberto 2014: 243-250). Es por ello que proponemos una serie de pautas que faciliten tanto los estudios como el trabajo de campo durante las intervenciones de conservación y restauración, así como un sistema de representación gráfica para poder establecer las relaciones y concordancias entre modelos y en definitiva ampliar el conocimiento que de ellos tenemos.

\section{Qué información se debe recoger}

Las dificultades antes mencionadas no han de impedir, incluso en las situaciones más adversas, registrar al menos su presencia en una obra. Las intervenciones de conservación y restauración son el momento propicio tanto para poder acceder a ellos como para analizarlos en profundidad, por lo queestos brocados se han de integrar en las correspondientes fases de estudio del conjunto de la tecnología de cada obra y de sus labores polícromas. Durante el trabajo de campo in situ la recogida de datos ha de ser ordenada, completa y sistemática, para luego ser analizados y contrastados, lo que garantiza la fiabilidad del método. 
A continuación se describen aquellos aspectos concretos del brocado aplicado que han de ser considerados y registrados en este tipo de estudios y que pueden seguirse en el esquema presentado en la Tabla 1, tabla que se incluye aquí como una guía para crear el formato de ficha que mejor se adapte a las necesidades de cada caso de estudio.
Como regla general cabe primero tomar aquellos datos correspondientes a la filiación de la obra como muestra el punto A. Obra de la tabla mencionada.

En el punto $B$. Identificación se indica el código de registro asignado a cada brocado (B.1), tarea especialmente laboriosa

Tabla 1.- Esquema de aspectos concretos del brocado aplicado

\begin{tabular}{|l|l|l|}
\hline \multicolumn{2}{|l|}{ A. OBRA } \\
\hline 1. & Denominación & Nombre de la obra (retablo de, escultura de, etc.) \\
\hline 2. & Ubicación & Inmueble (iglesia, museo, etc.) Municipio País \\
\hline 3. & Datación & Cronología \\
\hline 4. & Dimensiones & Alto, ancho y grueso \\
\hline 5. & Tipología & Retablo, escultura, pintura sobre tabla, pintura mural, artesonado. \\
\hline 6. & Material & Madera, piedra, etc. \\
\hline
\end{tabular}

\begin{tabular}{|c|c|c|}
\hline \multicolumn{3}{|c|}{ B. IDENTIFICACIÓN } \\
\hline 1. & Código & Un registro por cada brocado \\
\hline 2. & Localización & $\begin{array}{l}\text { Jerarquizado de lo general a lo particular. } \\
\text { Ej.: San Pedro, manto, envés, cenefa. } \\
\text { Circuncisión, sacerdote, túnica, envés. } \\
\text { Natividad, cortina, cenefa. } \\
\text { Natividad, castillo, portada. } \\
\text { Arquitectura: } 3^{\circ} \text { cuerpo, calle central, caja, fondo. }\end{array}$ \\
\hline \multirow[t]{2}{*}{3.} & \multirow[t]{2}{*}{ Motivo } & $\begin{array}{l}\text { Figurativo (vegetal -rosetas, trébol, flor de lis, flor, cactus, piñas-, zoomorfo, antropo- } \\
\text { morfo). }\end{array}$ \\
\hline & & Geométrico \\
\hline 4. & Técnicas asociadas & $\begin{array}{l}\text { Dorado, plateado, campo de color liso, laca o veladura, corla, aplicaciones, estofados, } \\
\text { láminas metálicas recortadas, etc. }\end{array}$ \\
\hline 5. & Relaciones (en la misma obra) & Ej.: Mismo motivo que H34 y C55. \\
\hline 6. & Relaciones (con otras obras) & Nombre de la obra (Incluir bibliografía de obras relacionadas). \\
\hline
\end{tabular}

\begin{tabular}{|c|c|c|c|}
\hline \multicolumn{4}{|c|}{ C. MORFOLOGÍA } \\
\hline 1. & Tipología & \multicolumn{2}{|c|}{ Yuxtapuesto (en hilera, escalonado), aislado, cenefa, otros (describir). } \\
\hline 2. & Forma de placa & \multicolumn{2}{|c|}{ Rectangular, cuadrada, romboidal, circular, octogonal, irregular, calado. } \\
\hline 3. & Dimensiones /diámetro & \multicolumn{2}{|c|}{ Alto, ancho y grueso, diámetro. } \\
\hline \multirow{9}{*}{4.} & \multirow{9}{*}{ Relieve } & \multicolumn{2}{|c|}{ Si/No. Diferentes niveles o planos (describir). } \\
\hline & & \multicolumn{2}{|c|}{ Dibujo del motivo Si/No (línea). } \\
\hline & & \multicolumn{2}{|c|}{ Contorno de placa y de zonas caladas. Si/No } \\
\hline & & \multirow{4}{*}{ Rayado Si/No } & Líneas por $\mathrm{cm}^{2}$ (de cima a cima). \\
\hline & & & Altura $(\mathrm{mm})$ variable de máx.-min. \\
\hline & & & Grosor (mm) variable de máx.-min. \\
\hline & & & Dirección (horizontal, vertical, diagonal) y grado de inclinación. \\
\hline & & Puntos Si/No & Grandes, medianos, pequeños \\
\hline & & \multicolumn{2}{|c|}{ Relleno de campos } \\
\hline 1. & Posición brocado/eje obra & \multicolumn{2}{|c|}{ Vertical, inclinado, volteado, etc. } \\
\hline \multirow{2}{*}{2.} & \multirow{2}{*}{ Color } & \multicolumn{2}{|c|}{ Si/No. Número de colores (nombrarlos). } \\
\hline & & \multicolumn{2}{|c|}{ Ubicación (sobre campo liso, relieve, fondo, sobre línea, etc.). } \\
\hline
\end{tabular}




\begin{tabular}{|l|l|l|}
\hline \multicolumn{3}{|l|}{ D. ESTRATIGRAFÍA Y MATERIALES } \\
\hline 1. & Aplicado sobre & Madera, piedra, aparejo, bol, dorado, plateado, color -opaco o veladura-, etc. \\
\hline 2. & Adhesivo & Si/No. Cola animal, huevo, mordiente, otros. \\
\hline 3. & Relleno & No de capas de relleno, composición, espesor, color. \\
\hline 4. & Estaño & Puro, aleación (peltre), espesor, color. \\
\hline 5. & Veladura & Si/No. Composición, color. \\
\hline 6. & Sisa (mordiente) & Si/No. Composición, color. \\
\hline 7. & Dorado & Si/No. Aleación, espesor, tamaño pan de oro. \\
\hline 8. & Color & Si/No. Pigmentos, aglutinante. \\
\hline 9. & Retoques originales & $\begin{array}{l}\text { Si/No. Ej.: oro para resanar una unión entre placas, fragmentos de brocado completan- } \\
\text { do huecos, pinceladas para resanar motivos, etc. }\end{array}$ \\
\hline
\end{tabular}

\begin{tabular}{|l|l|l|}
\hline \multicolumn{3}{|l|}{ E. ESTADO DE CONSERVACIÓN } \\
\hline 1. & Repolicromía & Si/No/Parcialmente \\
\hline 2. & Repinte & Si/No/Parcialmente \\
\hline 3. & Revestimiento (barniz) & Si/No/Parcialmente \\
\hline 4. & Permite la reconstrucción & Si/No/Parcialmente \\
\hline 5. & Observaciones & \\
\hline
\end{tabular}

a la hora de crearlos sobre todo en conjuntos retablísticos o portadas donde su presencia puede ser muy numerosa. La descripción de su localización (B.2) se organizará siempre jerárquicamente, de lo general a lo particular; por ejemplo en un retablo se indicaría primero el cuerpo y la calle, encasamento o elementos de la mazonería, para ubicar después imágenes y escenas y los ropajes donde se aplicaron. A continuación (B.3), se describe el motivo, si es figurativo o geométrico.

Luego observaremos las técnicas asociadas al brocado (B.4), pues interesa saber su relación compositiva con el resto de la policromía: dorados, plateados, campos de color liso, lacas, estofados, etc. (Carrassón 2012: 127). En el punto B.5 se toma nota de posibles relaciones entre este brocado y el resto de los existentes en la misma obra y posteriormente esta comparativa se podrá ampliar y completar con brocados de otras obras (B.6).

En el punto C. Morfología se especifica la tipología (C.1), si se trata de un brocado yuxtapuesto (en línea, escalonado...), aislado o el de tipo galón que aparece rematando las prendas. A continuación se verifica la forma de la placa de estaño (C.2): rectangular, cuadrada, romboide, circular (Carrassón 2007: 164), octogonal o irregular. Y como parte de su forma y diseño examinamos también si tiene calados, que no deben ser confundidos con lagunas o pérdidas de material.

Después se anotan las medidas (C.3), alto, ancho y grueso, o su diámetro.

Seguidamente atendemos al relieve de la placa de estaño (C.4) describiendo primero si ésta presenta diferentes niveles o cotas y comprobando después el relieve del motivo, el borde externo de la placa y de sus calados. Nos fijamos ahora en la presencia de estriados -líneas, rayasy puntos redondos en relieve, registrando en tal caso los siguientes aspectos de cada uno de ellos:

- Señalar en el motivo donde están trazados estrías o puntos.

- Indicar el número de estrías o puntos por cm2. Como norma se cuenta la cresta de la estría (no el surco entre dos estrías).

- Medir la altura y el grosor en mm de las estrías y de los puntos, respecto al plano superior de la placa, siempre que sea posible.

- Verificar la dirección del estriado en cada campo del brocado, si es horizontal, vertical, diagonal, irregular y, llegado el caso, su grado de inclinación respecto al eje del motivo.

Cabe describir también la posición del brocado respecto al eje de la obra, anotando si éste mantiene la verticalidad o se presenta inclinado respecto a la misma (C.5).

Finalmente, en este punto se registra el empleo de color, describiendo los colores usados y dónde se ubica cada uno -en campo liso, sobre las zonas en relieve o perfilando éste, etc.- (C.6).

El punto $D$. Estratigrafía y materiales, se refiere al examen material del brocado. Procediendo del interior al exterior señalamos en qué estrato de la obra se aplicó el brocado 
(D.1), por ejemplo: sobre madera, piedra, aparejo, bol, dorado, plateado, pintura, etc. Sondeamos si éste dispone de adhesivo o no y su naturaleza -cola animal, huevo, mordiente, cera, etc.- (D.2). Después nos referiremos al tipo de relleno utilizado en el reverso de la placa verificando su espesor, número de capas y coloración (D.3). Se indica la composición de la placa: estaño o aleación (peltre: 85 a 99\% estaño + 1-4\% cobre + ocasionalmente pequeña proporción de plomo) y su espesor (D.4). Una eventual presencia de veladuras sobre la placa de estaño vaya, o no, a ser dorada nos llevará a indicar también su color y composición (D.5). Prestamos atención ahora a la composición, espesor y color del mordiente para el dorado (D.6) y a las propiedades del pan de oro, tales como su grado de pureza y tipo de aleación (con plata, cobre o ambos), espesor y dimensiones (D.7). En cuanto al color aplicado sobre el dorado, se analizarán pigmentos y aglutinantes (D.8). Este análisis de la secuencia de estratos se completa con la revisión de posibles retoques originales, tales como resanados en la unión entre placas, utilización o aprovechamiento de fragmentos de brocados para rellenar huecos o repasos mediante pinceladas del motivo del brocado (D.9).

Tras el estudio del conjunto de datos obtenidos en el trabajo de campo se decidirá el tipo y alcance de los análisis de laboratorio necesarios para completar o cotejar las hipótesis planteadas. Previamente se habrá determinado la localización de las muestras a tomar teniendo en cuenta que deben elegirse aquellas que sean significativas para poder obtener conclusiones coherentes ${ }^{[6]}$.

Con la descripción de deterioros y alteraciones completamos este examen del brocado aplicado (E. Estado de conservación). Cualquier observación en este sentido es de interés para estudiar su estabilidad y comportamiento. Corresponde, por tanto, identificar estas alteraciones y deterioros relacionados con sus materiales constitutivos, su manufactura y su propia historia material que por su especificidad y extensión no es posible detallar aquí limitándonos en el presente trabajo a señalar la posible existencia de repolicromías, repintes o revestimientos -barnices- añadidos sobre los brocados (E.1, 2, 3). De su estado conservativo interesa saber si será posible deducir el motivo del brocado y si en tal caso podremos reproducirlo por completo o parcialmente a partir del calco para llevar a cabo su estudio comparativo (E.4), como se verá más adelante.

En cualquier caso, un espacio para las observaciones permite siempre incorporar aquellos datos que no estén contemplados o puedan presentarse de manera excepcional (E.5) ${ }^{[7]}$.

\section{Cómo tomar los datos}

Los diferentes ejemplares de brocado aplicado presentan generalmente una serie de aspectos comunes que conviene destacar. Como ya se ha dicho, a menudo se disponen sobre superficies curvas que no solo son difíciles de fotografiar sino incluso de visualizar y por ello de documentar. A esto se suma el reducido tamaño de las placas y de sus detalles compositivos. Su estudio se realiza frecuentemente in situ lo que obliga a disponer de importantes medios auxiliares para poder acceder a ellos $y$, como venimos señalando, la toma de datos puede verse condicionada por la inestabilidad de este material y las graves consecuencias que podría tener en su estado de conservación si no se actúa correctamente.

Por todo ello, es preceptivo empezar con un examen de conjunto de la obra para evaluar el tipo y número de brocados que contiene, su estado de conservación general, así como las limitaciones de acceso para disponer del equipo humano, de los materiales y de los medios auxiliares necesarios para estudiar pormenorizadamente sus características técnicas, plásticas, compositivas y su distribución en el conjunto.

A continuación se elabora ex profeso una ficha de campo donde se registran los datos de cada obra, ficha que posteriormente podrá volcarse en una base de datos. La Tabla 1 es una guía para la realización de las fichas de campo porque en ella se relacionan la mayor parte de las particularidades y situaciones que veremos en los brocados por lo que puede servirnos de ayuda para seleccionar los aspectos necesarios en cada caso de estudio. Se determinará el orden a seguir en la toma de datos de acuerdo al tipo y envergadura de la obra, ubicación y número de brocados existentes, estableciendo las claves de identificación que garanticen que cada brocado lleva su correspondiente código respecto al conjunto. Como se observa en la tabla no es suficiente que figure, por ejemplo en un retablo, sólo el nombre de la escultura o escena pues necesitamos saber en qué prenda se dispuso el brocado y si éste se aplicó en el exterior o en el envés de la misma.

En consecuencia, y como norma general, lo conveniente es la utilización de una sola ficha por brocado. Cuando haya varios repetidos en un mismo campo entonces se registran en la misma ficha, anotando si es posible su número.

La ficha de campo se completará con documentación gráfica que ilustre suficientemente las características técnicas y los motivos del brocado. Para ello, los métodos más usuales empleados son la fotografía y el calco directo, o ambos a la vez, recurriendo al dibujo a mano alzada cuando un brocado no sea accesible. El proceso de documentación se completará posteriormente con reproducciones y esquemas gráficos y, llegado el caso, con la reconstrucción de los motivos que permitan reconocer y comprender el brocado, como se verá más adelante.

\section{-Documentación fotográfica}

Es el sistema de documentación de menor riesgo para un 
brocado. La fotografía se realiza con una doble finalidad; documentarlos con la mayor fidelidad y disponer de datos válidos que nos permitan completar su trazado para estudiarlos; para lo cual se ha de contar con una adecuada iluminación y con una cámara fotográfica digital de calidad equipada con macro que permita aproximarse a la obra.

La toma fotográfica se realiza preferentemente con trípode, con el estabilizador de la cámara activado y con zoom para permitir su acercamiento y obtener los detalles representativos del motivo y de la técnica. Se recomienda usar el diafragma bastante abierto (11-13) y un tiempo de exposición prolongado, así como usar un disparador por control remoto o inalámbrico para evitar que salgan movidas.

En la toma de la imagen de cada uno de los brocados se ha de tener en cuenta las siguientes consideraciones:

Disponer siempre de una escala gráfica que en el caso del tamaño de los brocados es suficiente una de $5-10 \mathrm{~cm}$, a la que se puede añadir un talón con grados en milímetros. Debe ir colocada preferentemente en la parte inferior derecha e ir acompañada si es necesario con una microcarta de colores ${ }^{[8]}$. La escala de referencia que necesitamos tiene que estar inmóvil, en el mismo plano del brocado y debe sujetarse a mano para que no resbale ya que los brocados suelen estar generalmente en planos verticales o inclinados. Por razones obvias no se deben utilizar elementos adhesivos que puedan provocar manchas o desprendimientos de la policromía.

Cuando se realiza una fotografía con escala gráfica debe tenerse en cuenta la deformación esférica que provoca la lente, que puede corregirse aumentando la distancia focal del objetivo con ópticas macro y tele macro, y guardando suficiente distancia con el motivo para reducir el efecto.

El área de trabajo se iluminará preferentemente con luz natural para evitar aberraciones cromáticas derivadas de una inadecuada fuente luminosa; cuando esto no sea posible, se empleará iluminación artificial teniendo la precaución de emplear luminarias de tonalidad neutra (4000 K). La cámara se dispondrá frontalmente con respecto al motivo para evitar distorsiones. Por último, se recomienda completar la documentación fotográfica de los brocados con tomas de luz rasante, en ángulo de $45^{\circ}$, así como con iluminación ultravioleta ${ }^{[9]}$.

Un factor que falsea la percepción de un brocado fotografiado suele ser su presencia en la superficie curva de las esculturas, por lo que la opción, en estos casos, es realizar su restitución en plano a través de ortofotografía. Si tenemos en cuenta que se parte del motivo de la placa de brocado plana que se ha adaptado a la curvatura de la superficie, para corregir la fotografía se tiene que realizar el proceso inverso mediante software especializado ${ }^{[10]}$.

La fotografía digital permite el posterior tratamiento de estas imágenes con programas de edición de imagen vectorial, para obtener tanto una reproducción de los brocados como eventuales reconstrucciones en combinación con datos extraídos de los calcos o del dibujo a mano alzada. Esta reproducción, o primer dibujo técnico se convierte además en un documento fundamental que permite su copia, intercambio y crear infografías y gráficos explicativos en cualquiera de sus variedades tanto del brocado como del conjunto de la obra.

\section{-Calco}

Entre los métodos considerados, el calco directo es el más idóneo en tanto se obtienen los resultados más fidedignos al representar la escala real 1:1 del brocado y reproducir el relieve con sus particularidades e imperfecciones; aunque, como queda dicho, el motivo calcado se verá condicionado por su estado conservativo ${ }^{[11]}$.

Los materiales necesarios para su ejecución son básicos y bastante asequibles: plástico, rotuladores indelebles, lápices, goma de borrar, etc. El sistema requiere por un lado, colocar sobre la obra un plástico transparente en el cual vamos a calcar el motivo y por otro, que éste quede en la posición deseada durante todo el proceso. El plástico más apropiado es el de polietileno (o similar) de baja densidad, de 25-50 micras (galga 100-200) por ser más flexible y adaptarse mejor a las formas y volúmenes gracias a su electricidad estática, siendo posible prescindir de adhesivos, reduciendo riesgos para la obra en esta operación.

Dispuesto el plástico, se procede a calcar el motivo siguiendo un método concreto que parte de trazar el perímetro de la placa, el contorno y detalles de los motivos y su correspondiente punteado o estriado en relieve delineando con el rotulador la cima o cresta de las estrías. Se emplean rotuladores permanentes de color negro y punta fina $(0,75-1 \mathrm{~mm})$ que dejan trazos limpios y concretos. El color negro se usa para calcar el contorno y relieves de la placa mientras que recurriremos al tono correspondiente cuando el brocado disponga de colores.

Cuando no sea factible calcar todo el estriado por cuestiones conservativas u operativas, se reproducirá una parte significativa de cada campo, consignando tanto la densidad como la dirección del estriado, para terminar de dibujarlo más adelante. Es preferible completarlo inmediatamente con el brocado delante, pero a menudo se pospone realizándose con las tareas de gabinete, lo que requiere contar con los calcos, las fotografías, los esquemas obtenidos a mano alzada, etc. para reproducirlo.

El tamaño del calco quedará automáticamente registrado al imprimirlo agregando una escala gráfica a tamaño real 1:1, por lo que la reproducción siempre será fiable, puesto que la escala se amplía o reduce junto con el dibujo. En todo caso, cualquier calco que haya de ser escaneado, 
copiado manualmente e incluso fotografiado debe disponer siempre de una escala gráfica para que quede registrado su tamaño.

\section{-Mano alzada}

Un último sistema al que recurrir, ante las dificultades que entraña obtener un calco o tomar una imagen completa y sin deformaciones del brocado, es el dibujo a mano alzada. Completo o esbozado, es útil para documentar los modelos, ayuda a comprender mejor su diseño y puede ser completado cuando se disponga de otros ejemplos con su mismo trazado. En cualquier caso, el procedimiento implica tomar sus medidas para dibujarlo a escala real, de modo que se corresponda con la mayor exactitud posible al brocado ${ }^{[12]}$.

Como norma, calcos y dibujos a mano alzada han de conservarse siempre, con sus correspondientes referencias de localización, como parte del proceso seguido y constituyendo en sí mismos un documento significativo de los expedientes de las intervenciones en las obras.

A partir de tales documentos, realizaremos todas aquellas representaciones del brocado que consideremos necesarias con el fin de documentarlos, completar su conocimiento, realizar un estudio comparativo, exponer hipótesis de trabajo o simplemente para su publicación divulgativa. Ahora bien, cualquier tipo de representación gráfica derivada de estos originales, obtenida por cualquier medio, ha de seguir en lo posible una serie de pautas similares a las que se describen a continuación.

\section{Cómo se representan los datos}

La representación de los datos ha de seguir un proceso de elaboración estructurado y gradual que mediante determinadas convenciones gráficas nos permita plasmar en un plano las características del brocado -formas, relieve, color...- y realizar las comparaciones objetivas de sus modelos.

Obtenidos calcos y fotografías, este proceso entra en una segunda fase consistente en copiar-pasar a limpio- el calco para obtener un dibujo exacto del brocado en el estado que nos ha llegado. Esta copia a la que tomaremos como primer dibujo técnico estará sujeta a las consideraciones que siguen.

\section{-Dibujo del calco}

Es el resultado de reproducir un calco del que obtendremos un dibujo absolutamente fiel al original, sin ningún tipo de interpretación. Dependiendo del estado conservativo del brocado este dibujo será completo, parcial o fragmentario, pero siempre válido. Además, podrá mostrar un brocado total o parcialmente deformado, por encontrarse en pliegues o superficies irregulares, en cuyo caso lo consideraremos igualmente fidedigno; si bien, en función del grado de deformación que posea, no siempre nos va a dejar confirmar posibles relaciones con brocados de otras obras. Por ello, es importante que el proceso de copia o reproducción del calco, obtenido mediante programas de edición de imágenes o a mano, evite el perfeccionamiento del trazado del motivo y respete las particularidades e imperfecciones de su relieve. Si no fuese así, incumpliría la necesaria fidelidad al original.

La representación de pérdidas y lagunas de la placa de estaño se realiza mediante una línea discontinua [figura 1]. Debido a que el deterioro del brocado es un factor que interfiere a menudo en la comprensión de los motivos, éste sólo se representa en este primer dibujo, el que se ha copiado del calco -o de una foto, en su caso-.

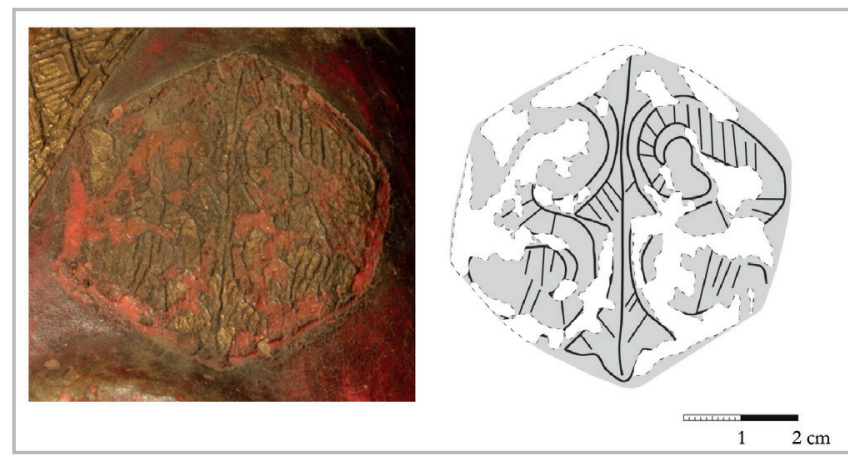

Figura 1.- Dibujo de calco. Escultura de San Miguel procedente de Troncedo, Huesca, actualmente en el Museo Diocesano de Barbastro, finales del s. XV. Brocado aislado situado en el manto, medidas $5,5 \times 5,7 \mathrm{~cm}$, estriado $7-8 / \mathrm{cm}$.

Dependiendo de las pérdidas o del estado fragmentario que presenten los brocados, podremos recurrir a reconstruir los distintos modelos a partir de estos primeros dibujos obtenidos de los calcos. Como se ve a continuación, para proseguir con su estudio planteamos dos tipos de reconstrucción en función del grado de fidelidad que cada una guarde con el original.

- Dibujo de reconstrucción: Es aquel que se realiza bien a partir de uno o con la suma de varios dibujos parciales o fragmentarios obtenidos mediante calco $\mathrm{u}$ otro sistema, con objeto de completar un mismo motivo. Pueden completarse las partes faltantes, pero siempre sobre evidencias que no den lugar a la especulación [figura 2].

- Dibujo hipotético: Se trata siempre de una propuesta o hipótesis de trabajo. El objetivo es completar por interpretación un modelo, a partir de uno o más dibujos del calco de brocados fragmentarios, sirviéndonos por ejemplo de los ejes de simetría del motivo o copiando los detalles que se repitan en el mismo. Por tanto, en la mayoría de los casos no será válido para confirmar si dos o más brocados salieron de la misma matriz [figura 3]. 

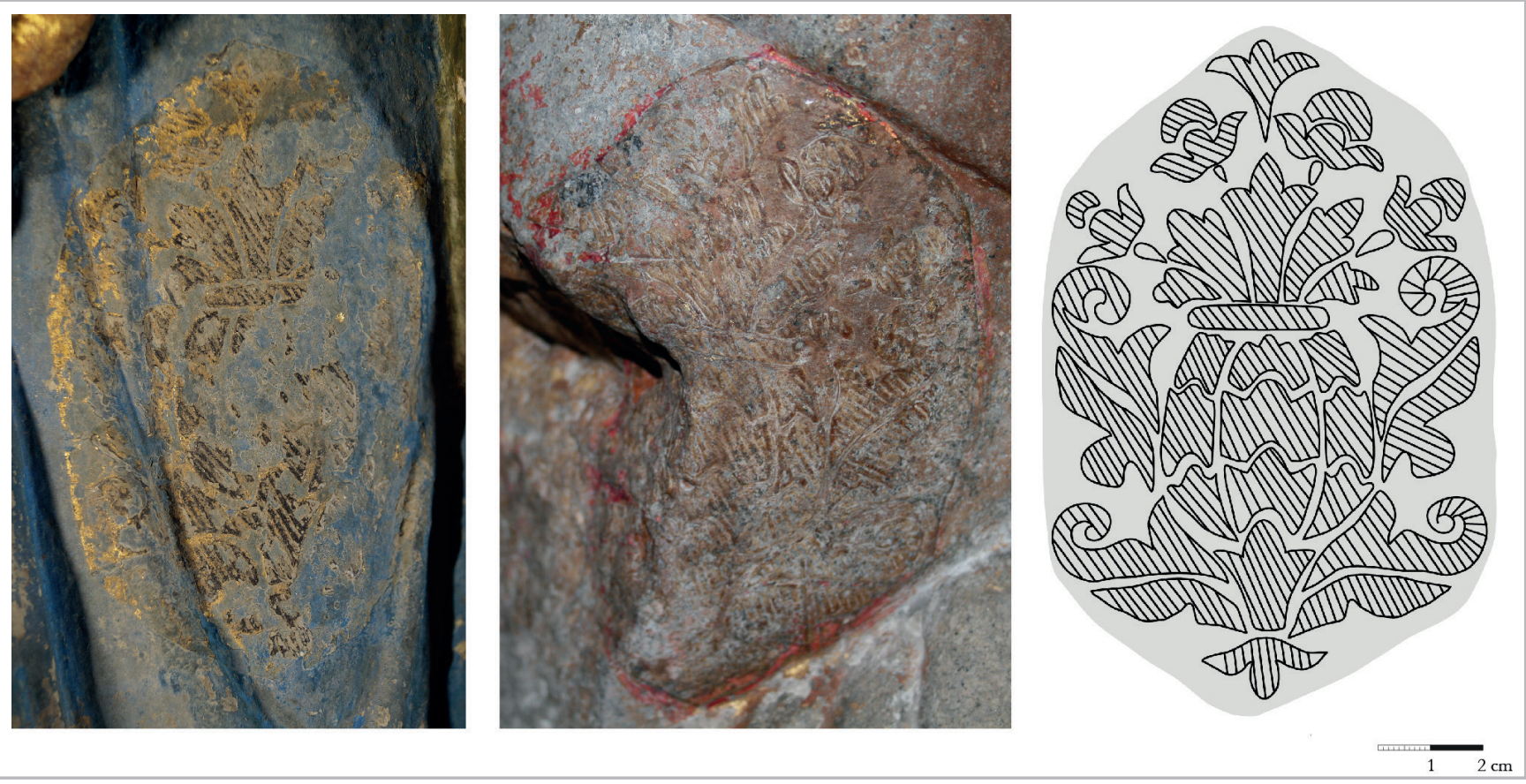

Figura 2.- Dibujo de reconstrucción. Pórtico de la Gloria, Santiago de Compostela. Brocado aplicado en la decoración del primer tercio del s. XVI, medidas $13 \times 8,5 \mathrm{~cm}$, estriado 6-7/cm: 2a. Fotografía de brocado dorado sobre fondo de azurita de la túnica del profeta Moisés. 2b. Fotografía del mismo modelo de brocado dorado, en este caso con campos de laca roja, aplicado sobre la dalmática dorada del apóstol San Pedro. 2c. Dibujo de reconstrucción realizado a partir de los calcos parciales obtenidos de varios brocados iguales.
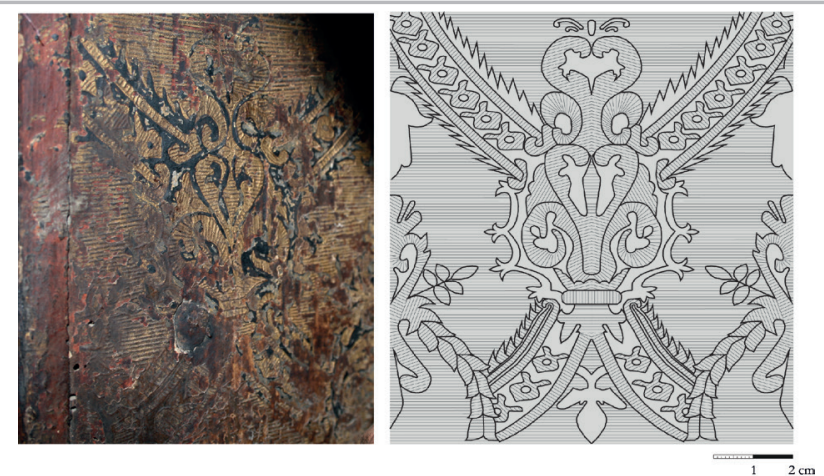

Figura 3.- Dibujo hipotético. Retablo de San Agustín, La Seo, Zaragoza, c. 1521. Brocado aplicado yuxtapuesto situado en la pared de la caja de la Anunciación del banco del retablo, medidas $11 \times 12 \mathrm{~cm}$, estriado 12/cm:3a. Fotografía del brocado con pérdidas. Presenta estriados, dorado y negro en perfiles y campos lisos. 3b. Dibujo hipotético obtenido por deducción de las partes faltantes.

Por lo que respecta al tratamiento gráfico para la representación de los motivos y características del brocado conviene dividirlo en dos gráficos individualizados como indica su denominación: grafico de relieve y gráfico de color. De este modo conseguimos una mayor legibilidad de las particularidades del relieve y del color y evitamos la habitual interferencia cuando ambos aspectos se hacen coincidir en un solo gráfico ${ }^{[13]}$. Esta doble representación se puede llevar a cabo en cualquiera de los tres tipos de dibujos a que recurramos, el primer dibujo del calco, el de reconstrucción o el hipotético, señalando en cada caso el dibujo del que proceden. Se describen a continuación unas pautas para su representación gráfica.
- Gráfico de relieve: Se trata de representaciones en blanco y negro. La forma de la placa de brocado se representa con un fondo de tono gris muy pálido (Color RGB: 221, 222,221 ), por lo que en caso de que el diseño de la placa presente calados éstos quedarán determinados por la falta de dicho color gris. La representación de los relieves de la placa -motivos decorativos, estriados y puntos- se hará con líneas negras continuas, incluido el contorno de la placa cuando su borde esté terminado en relieve [figuras 4 b y 5 c]. La variación del grosor de las líneas del estriado se plasma adelgazando o engrosando el trazo de las mismas. Si la placa de brocado tiene distintos niveles de altura los campos elevados se señalarán con negro.

- Gráfico de color: El habitual dorado de los brocados se representa coloreando el fondo con un ocre amarillo claro (Color RGB: 239, 173, 62). Mientras que el color o colores que completan el motivo se representan con el tono más parecido posible al original ${ }^{[14]}$. Sin embargo, si estamos ante el caso excepcional de un brocado plateado o simplemente el estaño está a la vista, sin dorado, se deja en tono gris claro cuando sea intencionado y no consecuencia de su deterioro [figuras 4 c y $5 \mathrm{~d}$ ].

Siempre que la información lo permita, se pueden superponer los dos gráficos anteriores jugando con la transparencia del color sobre el relieve o viceversa, haciendo posible observar al mismo tiempo relieve y color [figura 5 b] ${ }^{[15]}$. Sólo en el caso de brocados sencillos podemos representar todas sus características de relieve y color en un solo gráfico mientras no se interfieran entre ellas. 

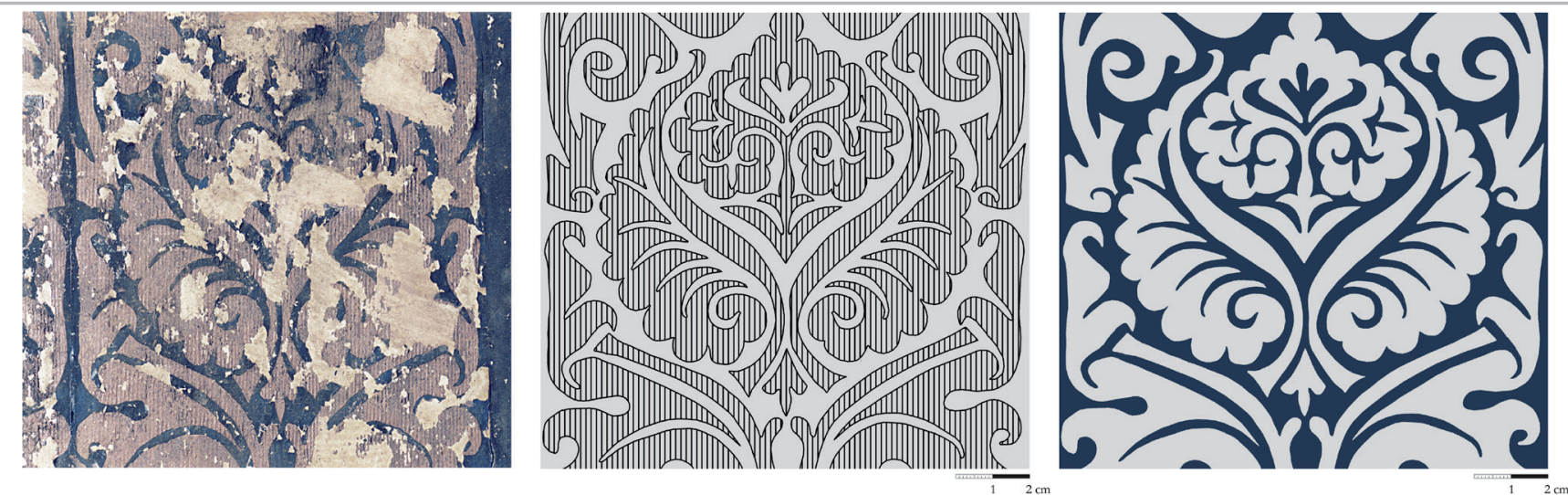

Figura 4.- Ejemplo de gráfico de un dibujo de reconstrucción. Retablo mayor de la parroquia de Nuestra Señora de la Asunción, La Puebla de Arganzón, Burgos, c. 1535. Brocado aplicado yuxtapuesto situado en las cajas del primer piso, medidas 32 × $21 \mathrm{~cm}$, estriado $12-13 / \mathrm{cm}$ : 4a. Fotografía de un brocado sin dorado, con el estaño a la vista y ligero recubrimiento no identificado; la tonalidad tostada corresponde a la masa de relleno, visible debido a la pérdida del estaño. 4b. Gráfico de relieve, muestra el contorno de los motivos y los campos con un estriado vertical. 4c. Gráfico de color, muestra el estaño a la vista sin dorado y los campos lisos con azurita.

Cuando resulte necesario, podrán realizarse todos aquellos dibujos y gráficos complementarios que ayuden a comprender las particularidades de los brocados, indicando siempre el dibujo del que procede cada uno. En el caso de los brocados continuos suele ser de interés reflejar el "montaje de yuxtaposición de placas", cuyo fin es mostrar el efecto general resultante, haciendo visible
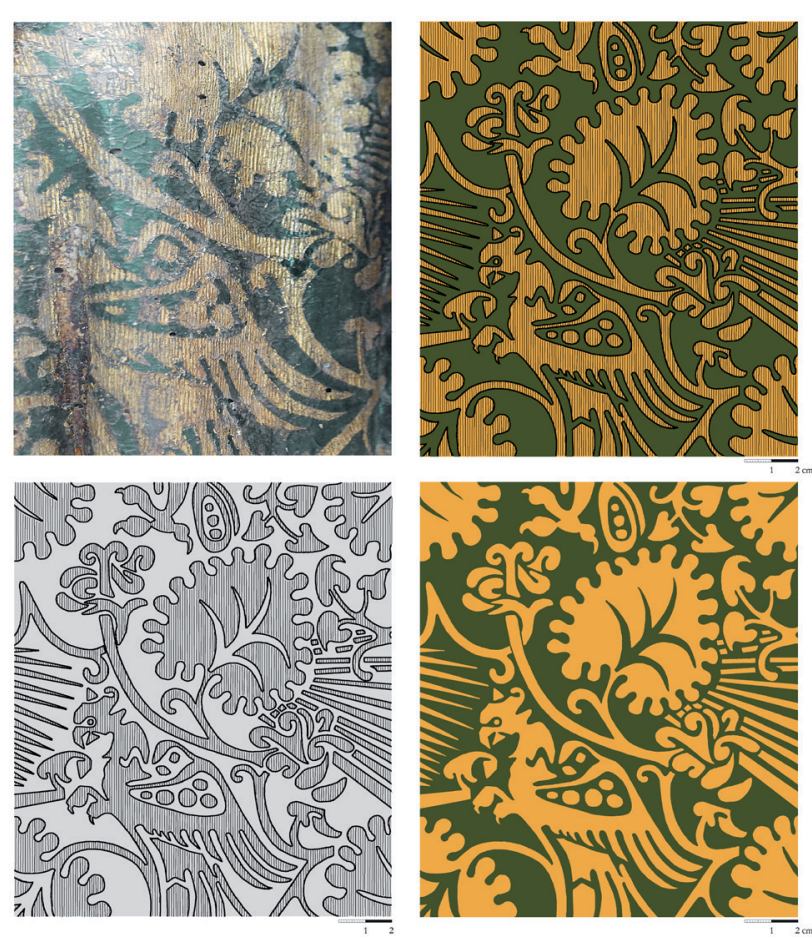

Figura 5.- Ejemplo de gráfico de un dibujo hipotético. Retablo de los Santos, antigua Colegiata de Covarrubias, Burgos, c. 1455. Brocado yuxtapuesto aplicado en el manto de San Pablo, medidas $16,7 / 8 \times 14,5 / 6 \mathrm{~cm}$, estriado 12-13/cm: 5a. Fotografía de brocado aplicado yuxtapuesto. 5b. Superposición de los gráficos de relieve y color. Este caso permite superponer ambos gráficos sin perder la información del relieve y del color. 5c. Gráfico de relieve, muestra los campos estriados y lisos y los contornos del dibujo. 5d. Gráfico de color, muestra el dorado y la veladura verde sobre los campos lisos. su composición. Este tipo de representación se realiza generalmente con cuatro placas idénticas [figura 6].

Si un brocado aislado está conformado mediante la unión de varias placas individuales, el nexo entre ellas se mostrará con una línea continua gruesa de color. Y cuando un brocado haya sido aplicado en diversos fragmentos, para adaptarlo a zonas de pliegues profundos, se pueden señalar sus uniones también con dicha línea gruesa de color.

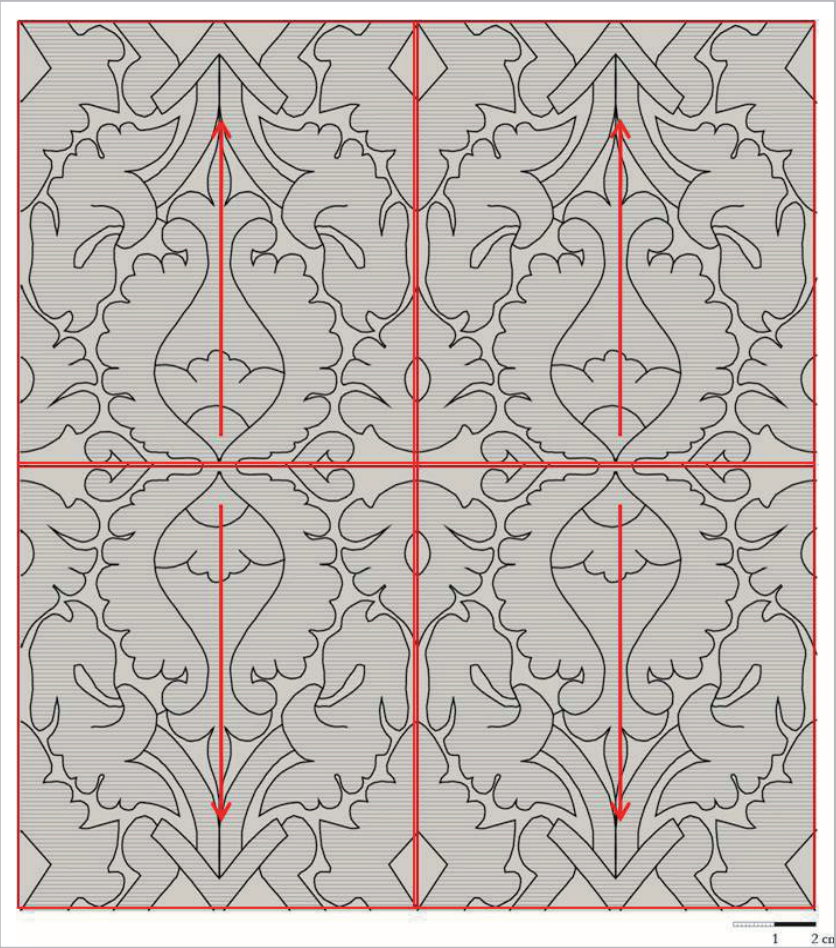

Figura 6.- Gráfico de montaje de yuxtaposición de placas. Retablo de la Visitación, Catedral de Tarazona, Zaragoza, c. 1525. Brocados situados en varias cajas del banco, medidas $10 \times 9 \mathrm{~cm}$, estriado 12$14 / \mathrm{cm}$. A partir de un dibujo de reconstrucción y con 4 placas de brocado se muestra su montaje, indicando con la flecha que en este caso las placas se dispusieron contrapuestas dando así continuidad al motivo. 
Del mismo modo, suele tener interés mostrar la distribución de los brocados sobre la obra. Esto permite visualizar cómo fueron situados los distintos modelos y observar el efecto creado con sus combinaciones. Se realiza sobre un plano, una fotografía o una ortofotografía de la obra, marcando con colores los tipos de brocado -yuxtapuesto, aislado, orlas o cenefas- o diferenciando cada uno de los motivos. Según los casos, se podrá emplear un trazo grueso rojo marcando el contorno de las placas o bien rellenar con un color cada brocado (si el trazo rojo se confunde con los tonos de la foto, se elige otro) [figura 7]. Si en cualquiera de los gráficos fuera necesario señalar el sentido de las placas se dispone en el interior de cada placa una flecha, mostrando la punta vertical, horizontal, inclinada o volteada [figura 6]. Por último, hay que considerar también la representación de las combinaciones y relaciones plásticas existentes entre el brocado aplicado y las otras técnicas de policromía: dorados, corlas, estofados, otro tipo de relieves aplicados o cualquier otra decoración.
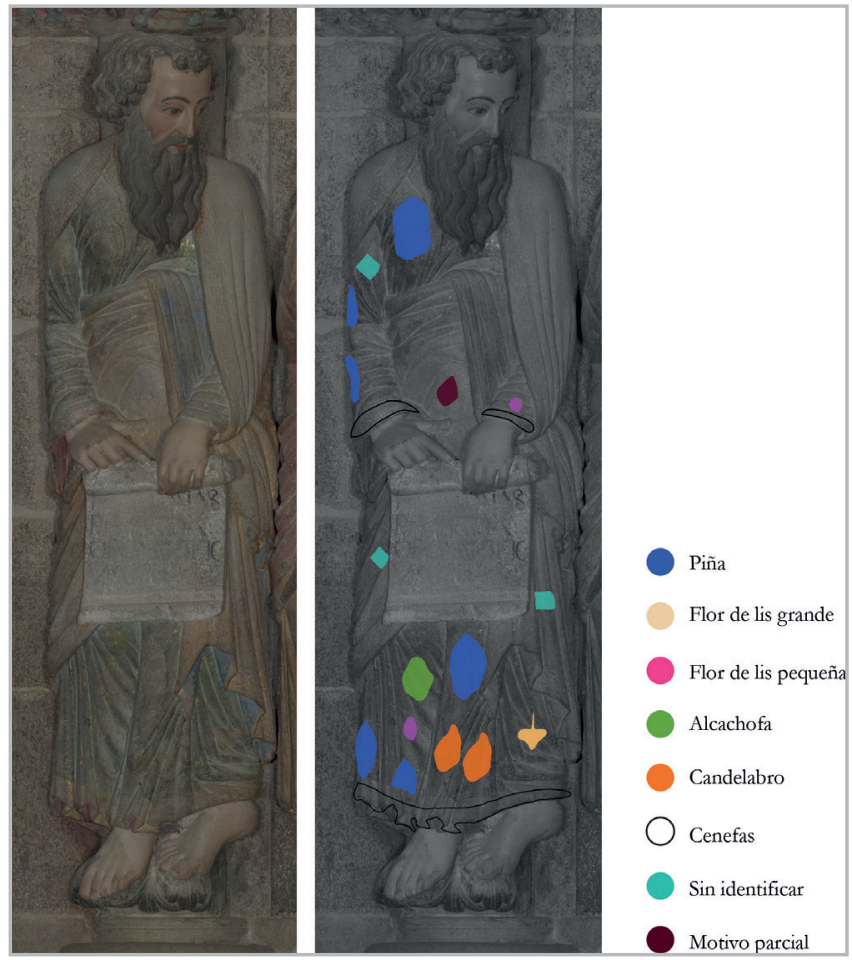

Figura 7.- Gráfico de distribución de los brocados sobre la obra. Pórtico de la Gloria, Santiago de Compostela, decoración del primer tercio del s. XVI. Repertorio de brocados aislados en la escultura del profeta Jeremías. @ Imágenes Archivo IPCE. 7a. Fotografía color. 7b. Fotografía en blanco y negro que muestra la distribución de los ocho modelos de brocados utilizados junto con su leyenda.

De forma general, dibujos o composiciones gráficas se ampliarán y adaptarán a su finalidad comparativa o al destino que se les quiera dar. En función del tamaño del brocado, o de un detalle específico que queramos destacar como un estriado o punteado, la escala puede ser mayor de 1 , de 5 o de 10 centímetros. Su composición puede obligar a corregir la resolución de los dibujos, adaptar el grosor de la línea representada o a recomponer la escala, siempre que el conjunto sea proporcional. En tales casos se siguen las convenciones descritas, colocando la escala en horizontal en la parte inferior derecha de las representaciones gráficas del brocado, en la zona donde estamos acostumbrados a ver estos elementos. Lo que resulta imprescindible es no olvidar la leyenda explicativa de la representación, que puede ser sencilla o más compleja en función de sus requerimientos.

El primer dibujo del brocado, realizado a partir del calco, es el documento que se incluye normalmente en los informes y memorias finales de conservación y restauración, a partir de él se realizan las reconstrucciones y representaciones necesarias para profundizar en el estudio de esta técnica del brocado aplicado.

\section{Conclusiones}

Esta propuesta metodológica que aquí presentamos siempre podrá ser ampliada o mejorada para adaptarla a la casuística de los brocados aplicados, así como a las nuevas versiones de los programas de diseño y tratamiento digital de imágenes, dado el previsible desarrollo tecnológico que posibilitará a corto o medio plazo disponer de nuevos métodos para lograr un registro aún más fiel de los brocados.

Además de proponer unas pautas para intentar sistematizar la representación de las características de los brocados aplicados -objetivo que dio lugar a la creación de este grupo de trabajo-, se expone un procedimiento describiéndolo en tres apartados: qué información se debe recoger, cómo se toman los datos y cómo se representan gráficamente los motivos y los aspectos técnicos del brocado para registrarlos y documentarlos. El sistema descrito, además de servir en sí mismo como aprendizaje, permite clasificar los brocados e identificar o deducir los procesos de producción y en definitiva poder estudiarlos desde distintos puntos de vista, válidos tanto para restauradores como para historiadores y otros estudiosos interesados. El avance en el estudio de esta técnica polícroma, como en el de cualquier otra, aumenta el conocimiento de la misma y fomenta tanto su conservación como las investigaciones históricas acerca de las técnicas de policromía y su evolución.

\section{Agradecimientos}

Queremos mostrar nuestro agradecimiento a las instituciones que nos han acogido para la celebración de las dos reuniones, la dirección del centro Gordailua y la del Museo Arqueológico Nacional. Así mismo a las personas de este grupo que coordinaron las jornadas Maite Barrio e Ion Berasain en Gordailua (Irún) 2018 y Ana Carrassón y Teresa Gómez en la celebrada en el MAN (Madrid) 2019. También nuestra gratitud a las coordinadoras del presente artículo: Ana Carrassón y Teresa Gómez. 


\section{Notas:}

[1] Actas do Congresso Internacional A escultura policromada religiosa dos séculos XVII e XVIII. Estudio comparativo das técnicas, alterações e conservação em Portugal, Espanha e Bélgica. Programa RAPHAEL. Lisboa, outubro de 2002. Ediçao: Instituto Português de Conservaçao y Restauro. Lisboa, 2004.

[2] Metodología para la conservación de retablos de madera policromada. Sevilla, mayo de 2002. Edición: Junta de Andalucía - The Getty Conservation Institute, Sevilla, 2006.

[3] El brocado aplicado es objeto de estudio de otros grupos de trabajo, como es el caso de la Universidad de Grenoble Alpes y la Agrupación de Interés profesional de conservación restauración Arc-Nucléart/Cea-tech, que organizaron en 2015 el coloquio Imiter le textile en polychromie. Le cas du brocart appliqué (en curso de publicación); o el proyecto más amplio e interdisciplinar PATRIMALP 2018-2021 que la Université Grenoble Alpes presentó en TECHNART 2019, Brujas, en un poster "3D structural imaging of heterogeneous materials: the study case of the applied brocade".

[4] La casuística técnica de los brocados aplicados puede ser muy amplia encontrándose a veces placas con partes caladas (Geelen \& Steyaert 2011: 79), motivos pintados a pincel sobre un estriado uniforme (Geelen \& Steyaert 2011: 219; Barrio y Berasain 2017: 110), etc. Sobre la técnica del brocado en general ver los trabajos de Mojmír S. Frinta, 1963, Brigitte Hecht, 1980 y Teresa y Giuseppina Perusini, 1983.

[5] No confundir brocados aplicados con aplicaciones de láminas de estaño pintadas que aparecen sobre la policromía, muy habituales en fechas anteriores.

[6] Como referencia para la toma de muestras en obras del Patrimonio Cultural se puede seguir la norma UNE-EN 16085:2012 de AENOR.

[7] Durante el registro de datos y con objeto de facilitar su comprensión se recomienda señalar en el apartado correspondiente con un guion (-) cuando efectivamente se constate la no existencia de alguno de los puntos examinados, mientras que si no podemos confirmarlo con seguridad utilizaremos el signo de interrogación (¿?).

[8] Utilizamos la referencia al color del sistema de colores RGB (Red, Green and Blue). Se trata del sistema más habitual en la industria digital, se encuentra en los programas Illustrator $\odot$ y Photoshop $\odot$ y en caso de impresión éstos programas de edición permiten su conversión al sistema CMYK (Cyan, Magenta, Yelow and Key) (Eguiluz 2006-2020; MonoGráfica 2017).

[9] En los casos que se emplee otro medio de documentación como fotos o video de teléfonos móviles, cámara de video, macro fotografía, ortofotografía, fotogrametría, etc. éste debe especificarse en la ficha de trabajo.

[10] Actualmente existe software de fotogrametría, tipo
PhotoScan (de Agisoft ()), que puede unir varias imágenes y reconstruir las coordenadas de la superficie y de los motivos, pero dichos programas siempre necesitarán unos puntos de referencia medidos a través de la colocación de la escala.

[11] Aunque los profesionales de este grupo de trabajo han ensayado y evaluado otros sistemas de representación gráfica como macro-ortofotografía, fotogrametría de imagen escalada, capturas de imagen con escáner o pruebas con rayos $\mathrm{X}$ hasta el momento no nos han permitido obtener resultados tan rigurosos como los conseguidos con el calco directo.

[12] Se han realizado así mismo puntuales ensayos para obtener el relieve mediante moldeo, un procedimiento que consideramos de alto riesgo, solo realizable por especialistas y que no creemos que sea un método adecuado para la conservación de la policromía.

[13] Estos problemas de legibilidad y otras circunstancias relativas a la representación de los brocados aplicados fueron el desencadenante para la presente normalización; una propuesta de Maite Barrio bien acogida y cuya consecuencia fue la formación de este grupo de trabajo.

[14] Entre los colores más recurrentes en los brocados están las lacas (rojos acarminados traslúcidos), el verde cardenillo, la azurita y en ocasiones el negro y el blanco. Debido a su variabilidad cromática, por composición o su estado conservativo, evitamos dar referencias fijas a utilizar, no obstante apuntamos algunos ejemplos empleados en casos concretos: carmín de laca roja (RGB: 192, 21, 37), azurita (RGB: 52, 101, 170) y verde cardenillo (RGB: 7, 71, 11).

[15] Al superponer los gráficos de relieve y color obviamente no es necesario el color gris claro usado en el primero, este paso es irrelevante trabajando con programas de edición con capas, pero en el caso de trabajos realizados con medios analógicos se puede prescindir del gris claro al superponerse estos gráficos ya que el amarillo que representa el oro a la vez señala la forma de la placa, mientras que cuando el oro no cubra la placa por completo esa parte quedará en gris.

\section{Referencias}

BARRIO OLANO, M., BERASAIN SALVARREDI, I., (2017). Applied Brocade in the altarpiece of the Coronation of the Virgin of Errenteria (Basque Country), Polychrome sculpture:Tool Marks, Construction Techniques, Decorative Practice and Artistic Tradition, ICOM-CC: 3: 106-115.

BARRIO OLANO, M., BERASAIN SALVARREDI, I., (2018). El Retablo de los Santos de la Colegiata de San Cosme y San Damián de Covarrubias (Burgos): estudio de la policromía. Ge-conservación, [S.I.], 13 (1): 29-40 https://doi.org/10.37558/gec.v13i0.569.

BERASAIN, I., BARRIO, M., (2006), "Consideraciones sobre el brocado aplicado en el retablo de la Puebla de Arganzón", Akobe, 7: 38-41. 
CARRASSÓN, A., (2007). “La Restauración” en El Retablo Mayor de la Iglesia Parroquial de San Pablo de Zaragoza. Restauración 2006, Zaragoza: 129-168.

CARRASSÓN, A., (2012). "Los procedimientos técnicos de la policromía del retablo mayor de Santa María de Tauste", El retablo mayor renacentista de Tauste, Carmen Morte García y Margarita Castillo Montolar (coords.), Zaragoza: Instituión Fernando el Católico (C.S.I.C.), 134-140.

EGUILUZ, J., Introducción a CSS, Uniwebsidad, https:// uniwebsidad.com/libros/css/capitulo-3/colores [Consulta: 12/06/2020].

FRINTA, M., (1963). “The Use of Wax for Appliqué Relief Brocade on Wooden Statuary", Studies in Conservation, 8(4):136-149, https://doi.org/10.1179/sic.1963.021.

GEELEN, I., STEYAERT, D., con la contribución de Cécile Glaude, Elisabeth Ravaud, Jana Sanyova, Steven Saverwins \& Wivine Wailliez (2011). Imitation and illusion: Applied Brocade in the Art of the Low Countries in the Fifteenth and Sixteenth Centuries, Royal Institute for Cultural Heritage, Royal Institute for Cultural Heritage.

GÓMEZ ESPINOSA, T., (2001). “Policromía del Gótico final. El retablo mayor de la Catedral de Toledo y obras burgalesas de Gil Siloe" en Actas Congreso Internacional sobre Gil Siloe y la Escultura de su época, Burgos: 573-582.

GÓMEZ ESPINOSA, T., GÓMEZ GONZÁLEZ, M., (2005). "Policromía tardogótica española", Ao Modo da Flandres, Disponibilidade, inovação e mercado da arte, Madrid: Fundación Carlos de Amberes: 265-278.

GONZÁLEZ-LÓPEZ, M. J., (2000). "Brocado aplicado: fuentes escritas, materiales y técnicas de ejecución", en PH Boletín, n 31: 67-77 https://doi.org/10.33349/2000.31.993.

HECHT, B., (1980). "Betrachtungen über Pressbrokate", Maltechnik, 1 Restauro: 22-49.

MONOGRÁFICA, (2017). RGB vs. CMYK: Una guía para diseñadores, https://monografica.es/rgb-vs-cmyk-una-guiapara-disenadores/ [Consulta: 13/06/2020].

NADOLNY, J., (2003). "The gilded tin-relief backgrounds of the Thornham Parva Retable and the Cluny frontal: technical and stylistic context", The Thornham Parva Retable. Technique, conservation and context of an English medieval painting, Cambridge: Hamilton Kerr Institute, 174-188.

PERUSINI, T., PERUSINI, G., (1983). “La tecnica del Pressbrokat nelli altare di Giovanni Martini di Remanzacco" en Restauro nel Fruili - Venezia Giulia, Belle arti e arti decorative. Manutenzione e riparazione, Diz.: 22, Memorie della Scuola Regionale di Restauro, 1: 28-35.

ROBERTO AMIEVA, C., (2014). El brocado aplicado en Aragón. Fuentes, tipologías y aspectos técnicos. Huesca: Estudios Altoaragoneses.

ROBERTO AMIEVA, C., (en prensa). "Aplicaciones y relieves con láminas metálicas en el Pórtico de la Gloria: el brocado aplicado" en La restauración del Pórtico de la Gloria, Ministerio de Cultura y Deporte, Madrid.

RODRÍGUEZ LÓPEZ, A., (2009). Análisis y clasificación de los brocados aplicados de los retablos de Guipúzcoa, Tesis doctoral, Universidad del País Vasco.

\section{Autor/es}

\section{Maite Barrio}

Conservadora-restauradora (Albayalde, San Sebastián) mbarrio@albayalde.org

\section{Ion Berasain}

Conservador-restaurador (Albayalde, San Sebastián)

info@albayalde.org

\section{Kyra Borst}

Arquitecta (Petra, S. Coop. Vitoria-Gasteiz)

info@petrarestauracion.com

\section{Ana Carrassón}

Conservadora-restauradora (IPCE, Madrid) ana.carrasson@cultura.gob.es

\section{Laura Ceballos}

Conservadora-restauradora (IPCE, Madrid)

laura.ceballos@cultura.gob.es

\section{Mercedes Cortázar}

Conservadora-restauradora (Petra, S. Coop. Vitoria-Gasteiz) mercedescortazar@gmail.com

\section{Isabel Cubillas}

Conservadora-restauradora (Petra, S. Coop. Vitoria-Gasteiz) icubillasq@gmail.com

\section{Ana Laborde}

Conservadora-restauradora (IPCE, Madrid) ana.laborde@cultura.gob.es

\section{Ingrid Geelen}

Historiadora del Arte (KIK/IRPA Bruselas)

ingrid.geelen@kikirpa.be

\section{Teresa Gómez}

Historiadora del Arte (MAN, Madrid)

titegespinosa@yahoo.es

\section{María José González}

Conservadora-restauradora (Universidad de Sevilla) baglioni@us.es 


\section{Agnès Le Gac}

Conservadora-restauradora (Univ. Nova Lisboa)

alg@fct.unl.pt / legac.agnes2@gmail.com

\section{Camino Roberto}

Conservadora-restauradora (Escuela Superior de Conservación y Restauración de Bienes Culturales de Aragón, ESCYRA)

croberto@educa.aragon.es / croberto@escyra.es

\section{Emilio Ruiz de Arcaute}

Conservador-restaurador (Servicio Restauración, DFA, Vitoria) eruizdearcaute@gmail.com

\section{Erica Sartori}

Conservadora-restauradora (Univ. Ljubljana, Eslovenia) erica.sartori28@gmail.com

\section{Ma Dolores Sanz}

Conservadora-restauradora (Petra, S. Coop. Vitoria-Gasteiz) mariadolores.sanz@gmail.com

\section{Delphine Steyaert}

Historiadora del Arte (Bruselas)

delphine.annie.steyaert@gmail.com

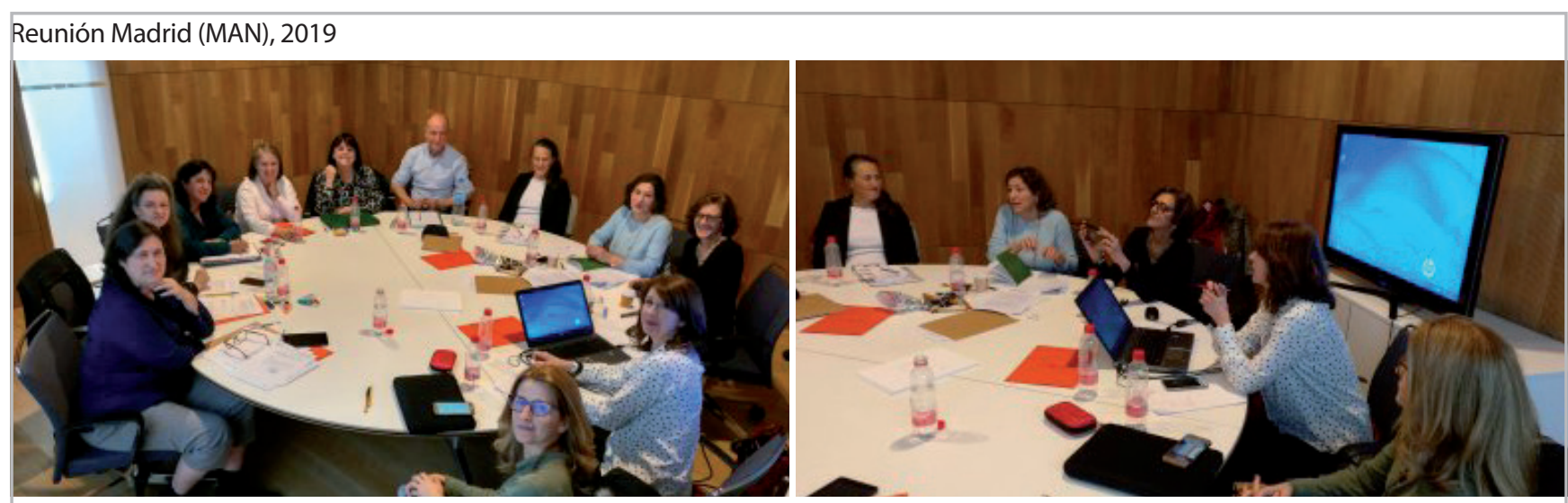

Reunión San Sebastián (Gordailua), 2018
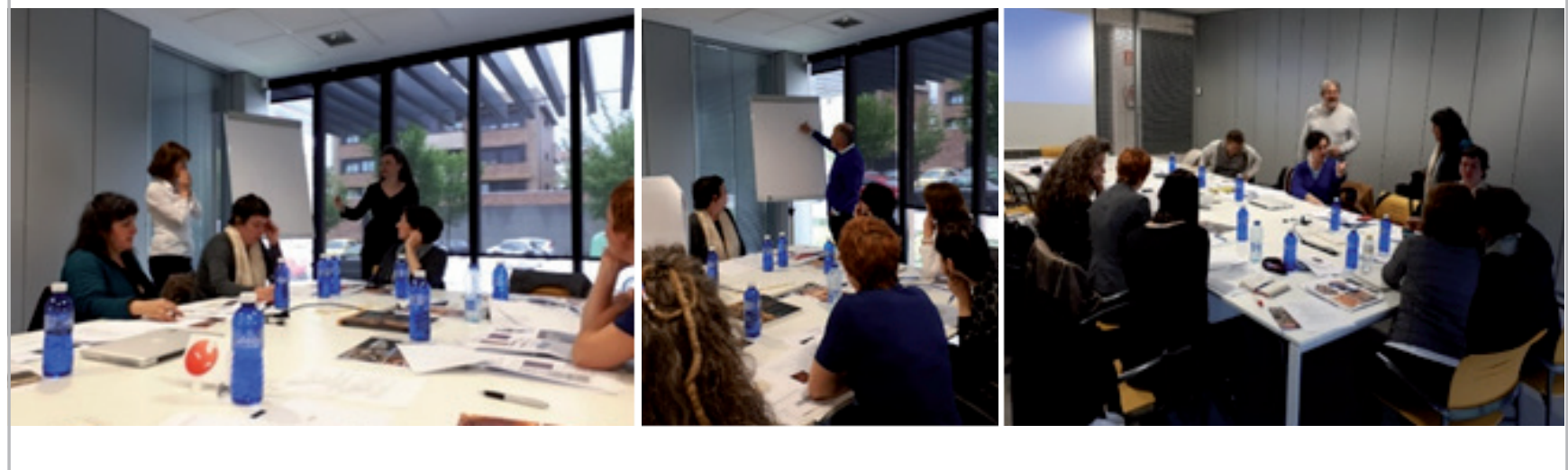

Artículo enviado el 28/09/2020 Artículo aceptado el 16/03/2021

(c) (1) $(\Theta$

https://doi.org/10.37558/gec.v19i1.844 